\title{
User Experience Model for Remote Envenomation Consultation Mobile Application with Decision Support Ability
}

\author{
Rasyida Zainun ${ }^{1, \text { a) }}$, Meng Chun Lam ${ }^{1, \text { b) }}$, Khairul Azmi Abu Bakar ${ }^{2, c)}$, Ahmad Khaldun Ismail ${ }^{3, d)}$ \\ ${ }^{1}$ Mixed Reality and Pervasive Lab, Center for Artificial Intelligence Technology (CAIT), Faculty of Information Science and Technology, \\ Universiti Kebangsaan Malaysia, 43600, Bangi, Selangor, Malaysia \\ ${ }^{2}$ Center for Software Technology and Management (SOFTAM), Faculty of Information Science and Technology, Universiti Kebangsaan \\ Malaysia, 43600, Bangi, Selangor, Malaysia
}

${ }^{3}$ Department of Emergency Medicine, Hospital Canselor Tuanku Muhriz, UKM Medical Centre, 56000, Cheras, Kuala Lumpur, Malaysia

Email: ${ }^{a)}$ P87565@siswa.ukm.my ${ }^{b)}$ lammc@ukm.edu.my ${ }^{C)}$ khairul.azmi@ukm.edu.my ${ }^{d)}$ khaldun_ismail@yahoo.com

\begin{abstract}
Most industries have begun adapting mobile technology in their daily work included health domain. A group of clinical toxinology experts intend to adopt the mobile technology to provide the consultation services remotely. Current practice of the consultation service is using the communication application available in market which has limitation and not suitable in their context. Thus, a specific newly design mobile application should be developed for their case. To generate mobile applications and services that meet the user's expectations, the development of applications that emphasize user experience (UX) factor needs to be implemented. UX factors are heavily depending on the different user, system, context and temporal factors. There is lack of research of UX factors in the mobile health domain especially in the remote envenomation consultation mobile application. Therefore, the purpose and scope of this research is to identify UX factors from the perspective of system components for this type of mobile application. This paper gathered the UX definition, UX factor and UX model from the previous researches. The UX factors finding process included literature review and discussion with the clinical toxinology experts. UX factors have been identified and matched with the remote consultation mobile application context. At the end, we have derived a UX model for the remote envenomation consultation mobile application case. The UX model included four product features and seven UX factor. Product features involved information quality, user interface design, functionality and data visualisation. Whereas seven UX factor involved usefulness, effectiveness, efficiency, ease of use, aesthetic, trustworthy and stimulation. The presented UX Model contained specific factor for remote envenomation consultation mobile application. It can be a reference to develop a mobile application to meet the context and user expectation for the remote consultation case.
\end{abstract}

Keywords - user experience; mHealth; remote consultation; user experiences factor; user experience models; factors influencing user experience.

\section{INTRODUCTION}

User expectation on mobile application are not only determine by the factors of easy to use or easy to learn. Good mobile applications also consider other compounding factors such as user satisfaction, interaction, excitement, stimulation and fun while interact with the applications. In order to generate a mobile applications and services that meet those criteria, the development of mobile application that adopt User Experience (UX) analysis needs to be implemented. User experience became essential and important role to the development of any software products. Because it has huge influence on the success or failure of a product, especially in the mobile technology industry as the mobile device itself has some limitations and constraints.

Research by [1], figured out four limitations that can affect UX mobile applications, that are power of the hardware poor, small screen, limited bandwidth and restricted operational interface [1]. Other limitations faced by mobile applications are screen clutter, information overload, limited interaction mechanisms or lack of keyboard and lack of task support [2]. These constraints contribute to several existence usability issues for mobile applications [3]. Based on the challenges and limitations listed, a UX designing method should be emphasized when developing mobile applications. User experiences analysis is proposed to address the negative effects of these constraints. 
User experiences analysis has to be conducted during specifying, designing, developing and implementing mobile application to matches the user's preferences [4] and to make mobile applications more effective, acceptable and useful. This can be done by looking and priorities the factors that positively influence UX in developing mobile applications.

The use of mobile technology or smartphones is growing rapidly and medical industry is no exception to experiencing a revolution through the development of mobile technology. In modern medical era, mobile technology is an integral part of the clinical practice and has enormous potential to improve the quality of service. In that regard, Remote Envenomation Consultancy Services (RECS) is one of the Malaysia community tend to take the advantage of mobile technology revolution. By utilizing mobile health (mHealth) in their work routine, their consulting services can be enhanced. RECS Malaysia was initiated by a group of emergency physicians who are also experts in clinical toxinology. They offers remote consultation services to healthcare providers in hospitals and clinics to manage patients affected by bites or stings of animals and other living organisms [5]. In the context of remote consultation, mobile applications have become an essential communication tool, which can provide a more convenient way for medical provider to get an appropriate and quick consultation from the experts. RECS plans to have a remote envenomation consultation mobile application with decision support ability.

There are various mobile applications developed healthcare domain. Among them are mHealth fitness application, developed for fitness trackers or exercise guides. Medical reference and Wellness application are developed to provide information on diseases, symptoms, medications and advice on how to take the right drugs or what to do if they are in pain. Another example is Medical condition management application was develop to provide information on a specific health condition. This application will track, display and share user's health parameters, medication intake and also patient feelings [6]. However, the application that focuses on remote envenomation consultation service with venomous creature specific for Malaysia culture is not yet available; therefore, the development of this mobile application is very much needed by RECS. The general communication application such as WhatsApp is using by the RECS team for the current practice. There are few limitations through the channel such as the message or conversation for the consultation is difficult to search back after the long discussion of the case. The animal or clinical information cannot be putted into a center references, hence, resending those information to the group is often. Another downside of using the general communication application is the organization and analysis or the previous case would take a huge effort. Every single piece of the case information has to manually capture and structure it.

A study of [6] proving a system with decision support has proven that it reduces medical errors and improves patient care. However, not all the developed applications are successful as expected. A specific design mobile application with decision support ability is needed by the RECS to improve the consultation service. The mobile application should able to organize the case especially the information about the incident, patient, organism and clinical progress. Other than that, an organism identification module is required to help RECS to make the species identification process faster. To make sure the developed mobile application more usable, knowledge on the UX is necessary.

In general, this paper aims to determine the factors that could measure the UX's quality of the remote envenomation consultation mobile application with decision support ability. By evaluating factors that may have the potential to influence the quality of UX, researchers and practitioners could benefit from it thus the design and UX of the mobile application could be improved.

This paper is compiled into five sections. Section I is the introduction. Section II discussed about material and method. Section III describes the result and discussion. In Section IV discussed conclusions of studies.

\section{MATERIAL AND METHOD}

\section{A. User Experience (UX) Definitions}

There are many definitions of UX proposed from different researchers, but the background and interests of the researchers influence these definitions. According to ISO13407, UX is the perception and response of a person resulting from the use or expectation of the use of the product, system or service [7]. While [8] defines UX can be perceived as affective and cognitive aspects of users towards the aesthetic and pragmatic perspectives of some particular product, service or system during and after interaction in some particular context. Expectations of users may influence the cognitive and affective aspects of users whereas overall UX can be affect due to different user groups and different social and cultural issues [6]. Referring to [9], UX is how users feel, how well they understand, how it works, how well it fits the whole context in which they are using it and how well it works with their goals. This means all aspects of how people use the interactive products [9]. [10] defines UX as all aspects of user engagement with its companies, services and products. The most important thing in UX is to accurately define user requirements and produce a product that is pleasing to possess and use [10]. [11] defines UX is the effect of the user's internal state, system features and context or environment in which interactions occur. The author describes the internal state of the user as predisposing, expectation, necessity, motivation and emotion. The features of the system are like complexity, usability, purpose and function. While the context is like organizational or social arrangement, meaning activity and voluntary use [11].

Generally, UX involves the emotion or perception of a person about using a particular product, system or service. Its highlights the significant aspects of human experience, human interaction and ownership of products. For each UX's definition, one or more factors are required to build the UX definition. These factors have been developed to assess the quality of products in the field of UX. More details on these factors will discuss on the following section.

\section{B. Factors that Influence UX from previous study}

In academic, different authors have been identified different factors that may affect UX in the use of mobile 
applications [6]. The factor is different is likely due to UX is highly subjective, dynamic and context that depend on the individual's value of the user and its context of use [12][15]. Furthermore, individual's experiences are unique, experiences will be changed by situations and time [12]. Therefore, designers need to design dedicated applications for mobile devices with consideration of their specific features and constraints.

Each mobile application has different mission, targets and developed for specific communities. That why every mobile application needs to identify their own UX factor in order to create the best user experience for user and thus encourage user acceptance. User experience covers the whole product or service acceptance [16]. Based on the literature review conducted, this section summarizes some of the dimensions and factors that affect UX in overall aspect.

The study by [17] attempts to create a UX framework that incorporates factors, dimensions and measurement methods. The purpose of the research is to unify the findings associated with UX's factors and dimensions together with the method of measurement that have been identified in a simplified theoretical framework of UX. The analysis results reveal multiple dimensions and UX factors. They suggested dimensions are value and overall experience, organizational brand experience, user experience needed, and technology experience. The finding for factors includes everyday operations, marketing, business communications, context of use, spatio-temporal, user journey, cultural, emotional, hedonic, trustworthiness, aesthetics, fun, privacy, sensual, usability, functionality, usefulness, platform technology, infrastructure, service response time, visual attractiveness and development process. The proposed new framework covered the dimensions of UX, the factors and methods of measurement are the results of the study [17].

According to [14], the concept of UX also involves several factors other than those described in the ISO 9126-1 quality model. Among the factors mentioned are reliability, attractiveness, usability, coolness, visual design, fun, functionality, stimulation and the other factors that play an important role for the successful of the product [14].

[8] conducted a case study on the mobile industry to identify factors affecting UX in adopting mobile products and services. They find that the factors that affect UX to mobile are user interface, internet service, computing factor, cognitive aspect, mobile accessories, multimedia and hardware factor such as battery, motherboard of mobile device, display screen and etc.

Study from [13] listed several factors and divided into four components, that are user, system, context and temporal component. User can be classified into novice, experienced, expert and focus group. In the system component, it contains category of physical and software. The physical category is physical hardware related including size, shape, orientation, height, reach and aesthetics. From the software category, factors that influence include factors such as functionality, usability, reusability, reliability, maintainability, portability and efficiency, correctness. In context component, it refers to the physical environment or location where users use the system. In terms of context, it can be seen from perspectives such as socio-cultural, market, time or historic, physical and use contexts. The temporal factors component describe about that UX of interactive systems can be captured before usage, during usage, after usage and over time usage [13].

From the diversity of factors used by previous researchers, it can be concluded that the UX factor can be divided into several components, which is system (hardware and software), user, context of use and temporal factors as in the study from [13]. These factors are more clearly defined in Fig. 1.

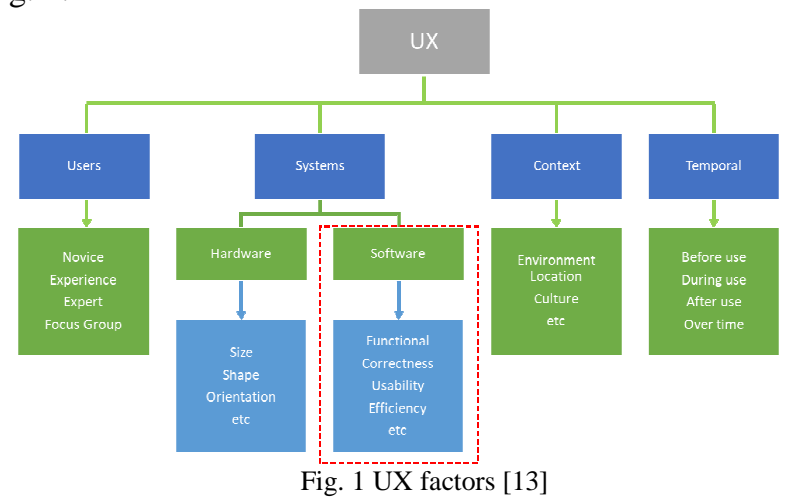

In this study, we focus on identifying factors from the perspective of system components (software categories), through previous case studies related to UX in the health domain. Next section describes some UX-related case studies in the health domain.

\section{Case Study Related to mHealth}

Although there are many related studies conducted, however, most studies are from different domains which suggested different factors from the healthcare domain such as study from [18]. They proposed a usability model comprising ten usability factors and four contextual factors. These factors need to be consider in the process of designing and evaluating mobile applications. Researchers as well as practitioners can use this model as a guideline for use for mobile applications [18]. Another study was focus on the usability of the eLearning management system. The study assesses Moodle applications and uses a heuristic evaluation approach to improve usability of the system in terms of satisfaction, ease of use and efficiency [19]. The study of [20] also examines the applications usability of the teaching and supervision evaluation system application by implementing eye-tracking techniques to improve the usability of the system [20]. Study from [16] identified UX factor for flight ticket booking mobile application, and suggest factor such as ease of use, user interface, learnability, security, user satisfaction, behaviour intent and environment as UX factor will affect the flight ticket booking mobile application [16]. While the study by [21] related to usability guidelines for elderly website interface, outlining the factor such as simple language, large font size, navigation that is easy to use and has a combination of media such as video and audio. Another example is the study from [22], they conducted the usability evaluation for Virtual Museum Environment (VME), Terengganu State Museum to collect data about the usability of the VME design by randomly selected respondents. Results obtained from the usability test in the aspects of navigation, manipulation and system control depicted that the VME prototype has fulfilled the three main 
elements of usability that are easy to use, efficiency and satisfaction.

For the health domain, a study of [23] on usability designs on iPhone and iPad for mobile cancer systems, identifies several few guidelines factors, which are functionality, learnability, ease of use, efficiency, easy manual, useful, usable, enjoyable, safety, security, effectiveness, satisfaction, aesthetic, minimalist and simplicity [23].

Research from [24] has explored and analysed acceptance factors from users perceptions, viewpoints and experience on the use of smart smartphone. They proposed Mobile Technology Acceptance Model (MoHTAM). The model indicated that a good design would increase the intention to use of mHealth applications. The MoHTAM study concluded that mHealth's design, particularly navigation and presentation of data on mobile devices has prompted users to use mHealth [24].

The study of [25] has assessed the acceptance and use of mHealth in pharmaceuticals based on a HumanOrganization-Technology-Fit (HOT-Fit) framework. Qualitative case studies to evaluate the use of mHealth technology from a pharmaceutical perspective were conducted in Malaysia hospitals and public institutions. Their study identified seven factors that affect the use of mHealth namely ease of learn, ease of use, overall satisfaction, perceived usefulness, clinical process, top management support and effectiveness of the healthcare service delivery [25].

Study by [26] has done a research to identify factors influencing the acceptance of decision support system (DSS) by using Unified Theory of Acceptance and Use of Technology (UTAUT) model for General Practitioners (GPs). Interviews were conducted to 37 GPs comprising a combination of diverse backgrounds of education, experience and gender. Their research identified four factors that influence the acceptance and use of DSS, including ease of use, usefulness, facilitating conditions and trust in the knowledge base [26].

In summary, several factors have been suggested by previous studies in mobile health applications. Each factor introduced has a different level of priorities depending on various factors and contexts of use. To ensure a good UX application development, UX design strategy needs to be implement by identifying UX factors that have a big impact on the remote envenomation consultation mobile application. In the next section, we will look in more detail the definition of each selected factor to confirm the suitability of the factor and theoretical basis for the development of UX model for the remote envenomation consultation mobile application with decision support ability.

\section{User Experience (UX) Factor Definition}

In this section, we have presented different UX factors identified by different authors. It is a broad area, some UX factor are more to the factor or aspect we need to take the consideration during the product design. For example, user factor, the experience of the user will affect the product (mobile app); for new user, we should prepare an overlay tutorial to teach the new user on how to use the mobile app.

In this paper, the UX factor refer to the factor that can be used to measure the quality of the product (mobile app) after finish developing. User Experience (UX) factor is a factor that can lead into a positive UX [27]. From literature review, the definition of factor provides different interpretations, some use different word for same definition. We have wisely chosen some UX factors relates to perspective of software that were found from the related studies as presented in Table 1. The factors listed in Table 1, are a collection of factors from previous literature studies from section II.

TABLE I

COLLECTION OF UX FACTORS FROM PERSPECTIVE OF SOFTWARE

\begin{tabular}{|c|c|c|}
\hline No. & Factor & Definition \\
\hline 1. & Learnability & $\begin{array}{l}\text { The ability of the application to allow } \\
\text { users to learn how to use them easily } \\
\text { and quickly [28]. }\end{array}$ \\
\hline 2. & Effective & $\begin{array}{l}\text { The ability of the application to enable } \\
\text { users to achieve certain tasks or goals } \\
\text { with accuracy and completeness in } \\
\text { certain contexts. Effectiveness also } \\
\text { defined as less error occur during } \\
\text { transaction [29]. }\end{array}$ \\
\hline 3. & Efficiency & $\begin{array}{l}\text { Less effort and time spend for user to } \\
\text { complete their task with speed on } \\
\text { achieving user goals [28], it refers to the } \\
\text { user ability in fulfilling these goals with } \\
\text { a minimum of effort [29], [24]. }\end{array}$ \\
\hline 4. & Ease of Use & $\begin{array}{l}\text { Easy to use the function or easy to read } \\
\text { the content. }\end{array}$ \\
\hline 5. & Aesthetic & $\begin{array}{l}\text { Related to visual appeal. It refers beauty } \\
\text { of the interface and how the user feels } \\
\text { about it [17]. The way the product looks } \\
\text { and works is simple, plain and } \\
\text { uncomplicated. } \\
\text { Related factor: } \\
\text { Attractiveness - other term for } \\
\text { attractiveness is aesthetics [29], beauty, } \\
\text { coolness, sexiness, desirability [27]. }\end{array}$ \\
\hline 6. & Usefulness & $\begin{array}{l}\text { How much the application is need to the } \\
\text { users and the product being useful and } \\
\text { meet user need [31]. }\end{array}$ \\
\hline 7. & Valuable & $\begin{array}{l}\text { The features are designed in such way } \\
\text { that support user needs, then the product } \\
\text { will be considered valuable [31]. }\end{array}$ \\
\hline 8. & Accessibility & $\begin{array}{l}\text { Available to all at any time. Degree of } \\
\text { usability for users with specified } \\
\text { disabilities [31]. }\end{array}$ \\
\hline 9. & Trustworthy & $\begin{array}{l}\text { Trustworthiness refers to the user } \\
\text { willingness to accept the information, } \\
\text { recommendations and results provided } \\
\text { by application [32]. }\end{array}$ \\
\hline 10. & Stimulation & $\begin{array}{l}\text { Stimulation is related to individuals } \\
\text { strive for personal development, } \\
\text { personal growth, proliferation of }\end{array}$ \\
\hline
\end{tabular}




\begin{tabular}{|c|c|c|}
\hline & & $\begin{array}{l}\text { knowledge and development of skills } \\
\text { [12]. }\end{array}$ \\
\hline 11. & Evocation & $\begin{array}{l}\text { This factor can bring amusement to the } \\
\text { user. Evocation also is about a user's } \\
\text { previous experience with a product [12]. }\end{array}$ \\
\hline 12. & Enjoyment & $\begin{array}{l}\text { Emotions during the usage of the } \\
\text { product [17], and [8] refer as joy to } \\
\text { own, joy to use, fun, sad, joy, afraid, } \\
\text { angry, frustrated, surprise [8]. }\end{array}$ \\
\hline 13. & Manipulation & $\begin{array}{l}\text { Manipulation relates to the pragmatic } \\
\text { factors of a product. Manipulation refer } \\
\text { to functionality of a product and how to } \\
\text { use its functions. Commonly, it relates } \\
\text { to utility and usability [12]. The aim of } \\
\text { a product should be clear to offer a } \\
\text { better understanding about how to use } \\
\text { it. }\end{array}$ \\
\hline 14. & Consistency & $\begin{array}{l}\text { Uniformity or similarity in the way that } \\
\text { products look, function and input or } \\
\text { output. }\end{array}$ \\
\hline 15. & $\begin{array}{l}\text { Error } \\
\text { Prevention }\end{array}$ & $\begin{array}{l}\text { System was able to prevent users from } \\
\text { making mistakes and if the error } \\
\text { happen, they can recover back [28]. }\end{array}$ \\
\hline
\end{tabular}

\section{E. UX Model}

Marc Hassenzahl UX Model were used in this study as a base and reference model. Marc Hassenzahl UX Model included three dimension, which is product features, apparent product character and consequences as shown in Fig. 2.

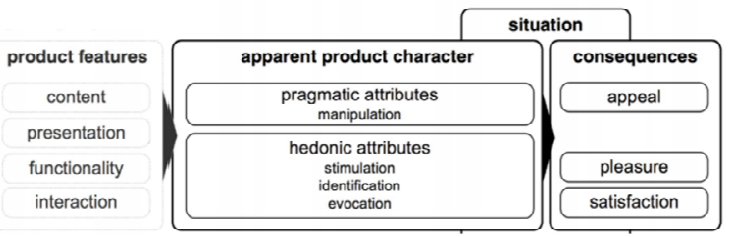

Fig. 2 Marc Hassenzahl UX model [12]

Product features has certain features, for instance content, presentation, functionality and interaction. A product characteristic will be comprised by pragmatic and hedonic factors. The pragmatic factors capture the usage and functions of the product, such as clear, supporting, useful and controllable. It emphasizes the fulfilment of individuals' behavioural goals. Whereas, the hedonic factors are more about the psychological states of user; It related to noninstrumental qualities such as aesthetics, innovativeness and originality [30]. Hedonic factors emphasize individuals' psychological well-being.

Using a product with a particular characteristic in a given situation will lead to certain consequences, such as emotional consequences and behavioural consequences. However, the consequences are not same because it might moderated by the specific or different usage situations and in various scenarios [12]. Hassenzahl model gives a systematic interpretation of user experience concept. The model provides dominant user experience principles and concepts to help the designers to adopt user experience concepts into the designing process. It has explained a clear perspective between user and product, which provides designer a guidance. The Hassenzahl model has been widely used in the contexts of human-computer interaction. We believe that Hassenzahl's model is an appropriate theoretical basis for addressing our research question which is what are the factors influence the user experience in remote envenomation consultation mobile application, because the model focuses on the factors that affect the experience of users in their interaction with the product, which is important in remote envenomation consultation mobile application context.

\section{RESULTS AND DISCUSSION}

\section{A. Current Workflow}

The user's needs for this application are obtained through a series of interviews with expert users, asking questions about their actual needs. At the same time, the current practice and data will be reviewed and collected to understand the user's needs and determine the context of mobile application usage. Among the information is the determination of the primary user, what is the urgent need for them and the context in which the mobile application will be used. In addition, documents such as patient health record form, manual work procedures and other documents are collected for analysis to gain a better understanding.

Currently, RECS experts rely heavily on manual methods or WhatsApp to provide consulting services. Based on analysis of the needs of current users and practise, the consultation process starts when healthcare providers are applying for consultations through WhatsApp application facilities. RECS consultant will identify or verify the venomous organisms include snakes, jellyfish, spiders, scorpions, bee or hornet, ant, centipede and stonefish. RECS consultants will then identify the species of organisms through observation of the case report either through the specimen image, bitten pattern or symptom. The healthcare providers will track systemic signs and conduct ongoing investigations and then send patients progress reports to RECS on a regular basis. Next management plan such as antivenom prescription will be suggested by RECS consultants depending on the progress of clinical data reported. Serious cases will be observed closely by healthcare provider and the progress must be updated to RECS consultants frequently for further treatment plan such as intensive care, medical care, surgery, discharged from hospital or requires follow up appointment with healthcare provider.

In the previous work, the framework for mobile applications with this decision support capability has been developed, it is named as MyRECS. The framework consists of three main components, healthcare providers, rules-based models and RECS consultants as shown in Fig. 3.

Fig. 3 illustrates how the patient management process is implemented. The process starts when a healthcare provider in an emergency unit at a hospital or clinic is applying for a consultation. New cases are created by recording basic demographic data of patients, images, clinical data and 
morphological characteristics of the organism. Healthcare providers are also responsible for filling out clinical data details such as medication records, observational charts of clinical developments, pain progress data, serial blood results and general checks. Details of the species will then be analyzed by a rules-based model for the identification of the involved organism species. Rules based models will recommend the most appropriate species. The next RECS will verify the species reserve created by the model and thus propose the best treatment plan for the patient [33].

From the current workflow, it can be concluded that the function of identification of species (organisms), the proposed treatment plan and clinical data reported are among the key functions of the mobile application. Certain factors that might increase user experiences of the mobile application need to be taken into account during the development of the mobile application. To achieve that goal, the UX model for remote envenomation consultation applications is recommended. The formation of this model is based on the theory of Marc Hassenzahl UX model and combined with the previous study's findings on mHealth. The proposed model will be described in the next section.

\section{B. Proposed UX Model For Remote Envenomation Consultation}

The developed model in this research (Fig. 4) is based on the Marc Hassenzahl UX model with some refinement for the remote envenomation consultation mobile application. From the Hassenzahl model, we understand many factors will influence a user's behaviour when using a product. Dimension of product features in Hassenzahl model includes content, presentation, functionality and interaction. In the context of mobile health application, [32] found that system and information quality are key features influencing use of healthcare application. With the high quality of information, it can help healthcare providers in making clinical decisions [29], [32]. This is agreed by [34], the output chart will be correct if the information quality of the system is good. This enhances the user's trust in systems capable of providing the right information and knowledge. Meanwhile, [3] found that information, visualization and user interface are important factor in mobile app. [8] also identifid user interface as a factor could influence UX in mobile industry. Additional, the model proposed by [29] for user experience indicated that product features such as functionality and user interface design will affect the interaction It is a major characteristics [28],[30].

Based on the finding from the literature review, several interview sessions with subject experts, identified process flows and the important components in the MyRECS framework, the proposed UX model includes four dimensions to indicate the product features for remote envenomation consultation service, which are information quality, user interface design, functionality and data visualization. Details description for every product features as shown in the Table 2 .

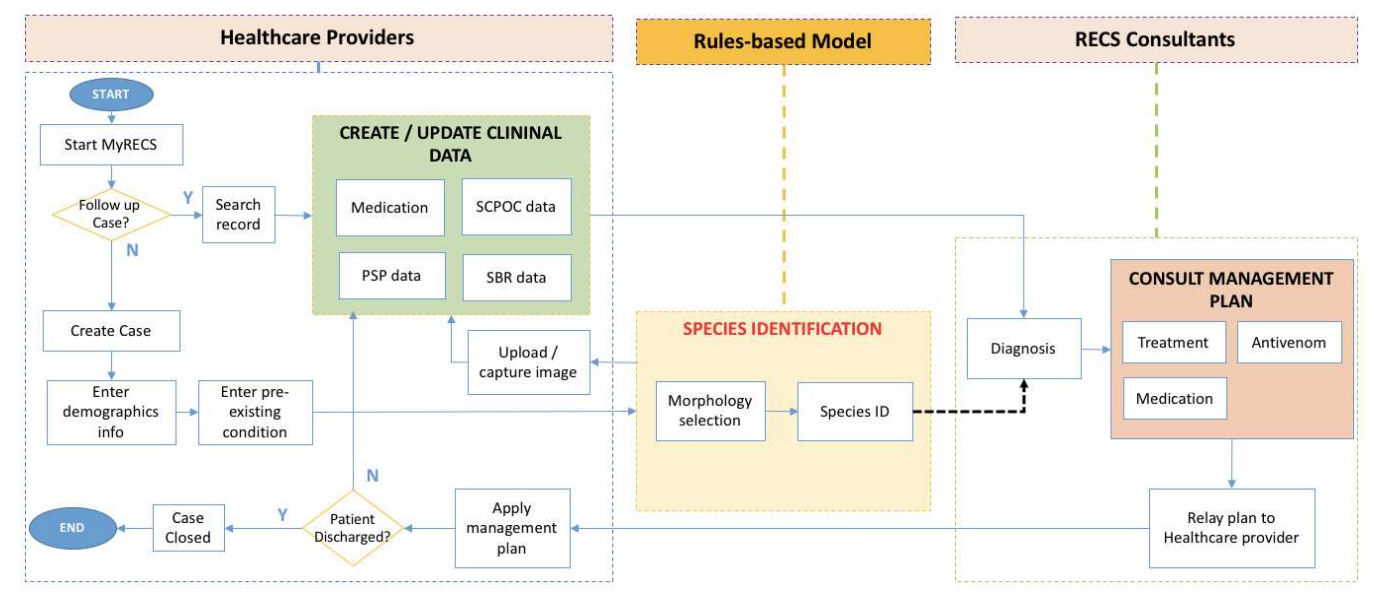

Fig. 3 MyRECS Framework [33]

TABLE II

PRODUCT FEATURES IDENTIFY FOR REMOTE ENVENOMATION CONSULTATION

\begin{tabular}{|l|l|}
\hline $\begin{array}{l}\text { Product } \\
\text { Features }\end{array}$ & Descriptions \\
\hline $\begin{array}{l}\text { Information } \\
\text { quality }\end{array}$ & $\begin{array}{l}\text { All texts contained in the remote } \\
\text { envenomation consultation mobile } \\
\text { application such as: }\end{array}$ \\
$\begin{array}{l}\text { General information relating to } \\
\text { venomous organism including species, } \\
\text { habitats, pictures, emergency assistance } \\
\text { and treatment to victims, } \\
\text { Procedure guidelines as doctors' } \\
\text { references to carry out medical }\end{array}$ \\
\hline
\end{tabular}

\begin{tabular}{|c|c|}
\hline & procedures called Infobox. \\
\hline User interface & $\begin{array}{l}\text { The place where human and machines } \\
\text { interacts with each other. }\end{array}$ \\
\hline Functionality & $\begin{array}{l}\text { Functions available in the app. Among the } \\
\text { functions that have been identified based on } \\
\text { user requirements are: } \\
\text { - User registration and authentication, } \\
\text { - Patient information and bite incidents or } \\
\text { stings, } \\
\text { - Identify species of venomous organisms } \\
\text { through specific algorithm including } \\
\text { species verification function suggested }\end{array}$ \\
\hline
\end{tabular}




\begin{tabular}{|l|l|}
\hline \multirow{V}{*}{} & $\begin{array}{l}\text { by toxinologists, } \\
\text { Treatment plan suggesting by } \\
\text { toxinologist, } \\
\text { - The function of recording the clinical } \\
\text { data } \\
\text { - Case search function } \\
\text { - Live chat with expert }\end{array}$ \\
\hline Visualisation & $\begin{array}{l}\text { Data visualization helps people understand } \\
\text { the importance of data by putting it in a } \\
\text { visual context. The use of visualization } \\
\text { facilitates translation of patterns, trends and } \\
\text { data correlations. } \\
\text { Two things that require visualization data on } \\
\text { remote envenomation consultation mobile } \\
\text { application are patient clinical data and case } \\
\text { statistics. }\end{array}$ \\
\hline
\end{tabular}

The entire factor listed in Table 1 might be important for influence UX positively. Based on related literature review from mobile healthcare domain, we find that the following factors are a good foundation to include into the UX model for remote envenomation consultation mobile application as shown in the Fig. 4. The factors that affect UX are usefulness, effectiveness, efficiency, ease of use, aesthetic, trustworthy and stimulation.

As discussed in part II, the factors affecting UX are different for different context. In this regard, the factor selection for this study is based on previous studies of mHealth-related applications and decision-support systems from the perspective of software categories. The identified factors and the justification in the remote envenomation consultation mobile application context are discussed as below:

Usefulness - A study from [26], found that the usefulness is important finding in her study on acceptant of decision support system among general practitioners. User will adopt the application if they find it is useful to them. [34] also proposed that information quality positively affects perceived usefulness. According to [35], the usefulness is the most important factor for determining the intention of the user on the website. For remote envenomation consultation mobile application, usefulness related to information quality, functionality and data visualization, where:

- Information quality: Only information that is useful and reliable to users is displayed. For example, information related to the venomous organisms that exist in Malaysia and guidelines for implementing health procedures for victims of venomous poisoning. Applications that contain irrelevant or overload information may trigger a negative user experience. Besides, information providing must be updated, detailed and accurate.

- Functionality: All functions provided by the application are functions that have been identified must be useful to users. Data entry for case creation and monitoring needs to be minimal and avoid non-essential fields.

- Data visualization: Only data or statistics required are generated and visualized. Therefore, the application should provide convenience for users by illustrate patient clinical data (medication record, serial clinical progress observation chart, pain score progression data, serial blood results and general examination) and case statistics.

Effectiveness - Effectiveness is the ability of users to complete tasks in specific contexts. It ensures accuracy and completeness of the information and output of the application. Accuracy and completeness of information can prevent mistakes. For remote envenomation consultation mobile application, effectiveness affect by information quality, functionality and data visualization, where:

- Information quality: Any information related to venomous organisms, statistical number of case, guide to implementing medical procedures and other information need to be display accurate and complete.

- Functionality: Identification the species of venomous organism function needs to produce the right result. Error in the species prediction can cause major effects such as improper treatment which can be life threatening. In this application, the species result produced by the algorithm must be verify or can be edited by the RECS expert to ensure correct species involves in the incident. According to [29] effectiveness will minimize errors. By reducing the application errors, it can increase the users' intention to use the application.

- Data visualization: Data must be shown in real-time and use the appropriate visualization techniques to make remote envenomation consultation application readable. In remote envenomation consultant, the clinical data of patients recorded periodically, should be accurate and clearly displayed to facilitate the analysis of patient's condition. 


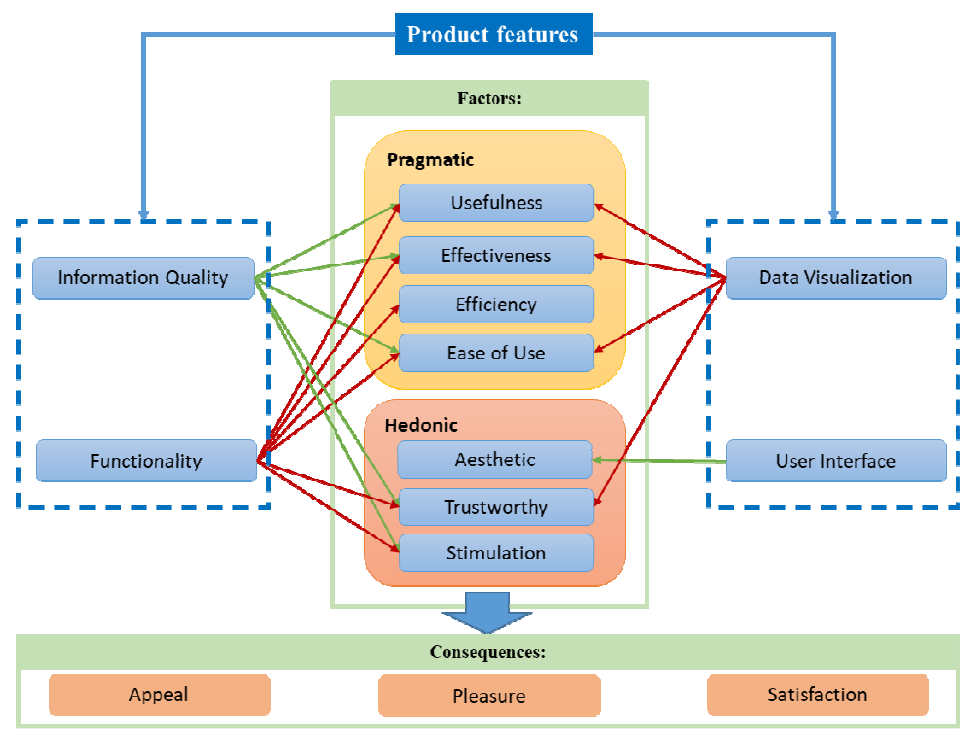

Fig. 4 Remote envenomation consultation mobile application UX Model

Efficiency - Relate to time and speed. It is very crucial to an application. Users are more interested in applications that can achieve their goals quickly. On the other hand, applications that cause users to spend too much time before to achieve their goal can cause reduce the interested in using them. The more efficiency, the more satisfying it will be to the user. For example, the process of data entry is designed effectively and as efficiently as possible through design manipulation. Hence, best practice in designing of the input forms for mobile application should be used, such as identify only important data that needs to be included in the form and simplify the process. Use the right keyboard to match with data input. For example, if the field requires phone number entry, the numeric keypad should be provided to the user so they can enter numbers easily.

Ease of Use - Easy to use functions or read content as well as users can handle and control applications easily. A study from [26] agrees that ease of use is one of the main factors influence decision support system acceptance and use. For remote envenomation consultation mobile application, ease of use can be achieved by ensuring:

- Information quality - Ease of reading page content, ease of recognizing information, affordance and findability of information needed quickly. User also ease to interpreted or understand the displayed information.

- Functionality: Ease of use means the function is easy to use, ease of operation, as simple as possible and can be easily understand for everyone. Simple operation such as ease to input data, ease to use output and ease to learn (learnability). Designers should try to minimize the steps involved in the process to facilitate them, as the number of steps taken to complete the transaction has a huge impact on ease of use. For example, when designing user interface, a horizontal label alignment should not exceed the boundary of the phone screen. It will cause user to perform unnecessary action to scroll to the left or right of the phone.

- Data visualization: the presentation of clinical data and statistic of cases should be easily interpret. Clinical data visualization results can help the specialist in defining treatment plans for patients. If the application is difficult to use, users will usually leave the application in frustration.

Aesthetic - Based on [8], the look and feel of the product/service should be attractive [8] and presenting information in appropriate format. Users should have a fun, pleasant and wonderful experience during interaction with the mobile application. The findings of their study have shown that a simple interface design contributes to positive user satisfaction. The visual design with the look and feel of the application can have a great impact on the users' emotions. For remote envenomation consultation mobile application, user interface is the first thing the user sees and affect the impression of the application capability. Icon selection needs to be precise as it is key to delivering accurate information. Icons must be simple and meaningful that can improve user perceptions on the meaning [16]. By using right icon, user could identify content meaning by the icons correct and quicks. People should not have to analyse the icon to figure out what it represents, for example the use of the relevant species icon organism to show that the organism species would make it easier for users to recognize the icon with a glance over text usage. The use of proper fonts and colours will also increase the aesthetic value of the application interface. Different data graphs, represented by colour differences. Therefore, users can see the difference of each graph that represents different data easily. In this regard, we believe an appropriate in arranging layout information and well-designed interface will enhance pleasure. Therefore, a good designer needs to arrange interface elements according to the cognition and emotions of users.

Trustworthy - It relates to the user's trust to the knowledge base and all the information contained in the application and it became an enabler of decision support system use [26]. In the study of [36], found trusts is a fundamental factor for a user to accept a system. The study is about factors affecting e-government system adoption in 
Indonesia [36]. With the trust, user will feel comfortable in using it. If user did not trust with the information provided by application, user definitely would not be use the application. For remote envenomation consultation mobile application, trustworthy must include as follow:

- Information quality: Accuracy, relevant, updated and complete information about guidelines in handling patient will increase trust to the information.

- Functionality: Suggested species of organisms by application through specific algorithm must be verified by toxinologists expert to make sure the accuracy of species, this can increase user trustworthy to the application.

- Data Visualisation: The resulting visualization is trusted by the user and can assist the medical practitioner in making decisions based on the visual data displayed.

Stimulation - Related to professional development, stimulation is able to make users believe that their professional skills can improve with the application. Professional development factor can influence positive usage of the application [25]. So remote envenomation consultation mobile application must have this feature through:

- Information quality: The provision of information regarding venomous organisms and procedures for carrying out procedures allows users to recall or improve their knowledge in the field.

- Functionality: With identification species function, users can improve their ability to know the species indirectly. The case search function will help users refer back to relevant old cases and facilitate the handling of new cases. Through frequent use will enhance skills in the identification of species and handling of victims of venomous bites.

Consequences is a result from user experience when or after interacting with the application. The UX model for remote envenomation consultation with decision support ability is expected to have a positive impact on users such as appeal, pleasure and satisfaction. It is the consequences mentioned in the Marc Hassenzahl UX model.

In summary, there are seven factors identified that are usefulness, effectiveness, efficiency, ease of use, aesthetic, trustworthy and stimulation. Those factors have been selected after the review on the previous UX research and after the consideration of the context of mobile application for remote consultation that will be developed and used by the Malaysia community later.

\section{IV.CONCLUSIONS}

It is very important for mobile application designers to understand the concept of user experience and to identify factors that significantly affect UX positively to ensure mobile applications reach the highest level of customer expectation and acceptance. Based on the previous studies, we have derived a UX model for the remote envenomation consultation mobile application case, there were four product features and seven product factor that have been explained under the model. Product features involved information quality, user interface design, functionality and data visualisation. Whereas product character involved usefulness, effectiveness, efficiency and ease of use under pragmatic factors and aesthetic, trustworthy and stimulation under hedonic factors. All of these factors play a significant role to develop a good user experience for remote envenomation consultation mobile application.

For the future work, this model will be used to plan the development of remote envenomation consultation mobile application prototypes to ensure the mobile application meets user requirements and then perform a user experience assessment to determine the UX level.

\section{ACKNOWLEDGMENT}

This study is part of the research funded by GUP-2017050. The authors would like to thank the Remote Envenomation Consultation Service (RECS) Malaysia for their support and encouragement.

\section{REFERENCES}

[1] Y. Xiao, Y. Tao, and Q. Li, "A new mobile web presentation with better user experience," Proc. - Int. Conf. Networks Secur. Wirel. Commun. Trust. Comput. NSWCTC 2009, vol. 1, no. c, pp. 137-141, 2009.

[2] Y. Sun, W. K. Chong, Y. Han, S. Rho, K. L. Man, and A. R. System, "Key Factors Affecting User Experience of Mobile Recommendation Systems," vol. II, 2015.

[3] J. L. Wesson, A. Singh, and B. van Tonder, "Can Adaptive Interfaces Improve the Usability of Mobile Applications?," pp. 187-198, 2010.

[4] A. Suzianti, R. P. Minanga, and F. Fitriani, "Analysis of User Experience (UX) on Health-Tracker Mobile Apps," vol. 9, no. 4, 2017.

[5] A. K. Ismail, A. Adnan, A. Hassan, Z. Mohamed@ Ismail, and R. Daud, "Remote Envenomation Consultation Services (RECS) for Healthcare Providers in Malaysia," 2nd Oxford World Symp. Venoms (Venoms 2013), St Hilda's Coll. Oxford, UK., p. 2010, 2013.

[6] A. Mourouzis, I. Chouvarda, and N. Maglaveras, "Mhealth: Common Usability and User Experience Practices and Flaws," Eur. Mediterr. Middle East. Conf. Inf. Syst. 2015, vol. 2015, pp. 1-16, 2015 .

[7] I. 2010 and I. Standard, "ISO 13407," vol. 1999, 1999.

[8] A. Mansoor, Z. Mahboob, and J. Winter, "User Experience Evaluation in Mobile Industry," no. January, 2011.

[9] L. Alben, "Quality of experience," 1996.

[10] D. Norman and J. Nielsen, "The Definition of User Experience (UX)," Nielsen Norman Gr. Publ., p. 1, 2016.

[11] M. Hassenzahl and N. Tractinsky, "User experience - A research agenda," Behav. Inf. Technol., vol. 25, no. 2, pp. 91-97, 2006.

[12] M. Hassenzahl, "The Thing and I: Understanding The Relationship Between User and Product," Funology from usability to enjoyment, pp. 31-42, 2003.

[13] Ahsanullah, S. Suziah, M. Kamil, and K. Muzafar, "Understanding Factors Influencing User Experience of Interactive Systems: a Literature Review," vol. 10, no. 23, pp. 18175-18185, 2015.

[14] C. Jetter and J. Gerken, "A simplified model of user experience for practical application," 2nd COST294-MAUSE Int. open Work. "user Exp. - Towar. a unified view.," pp. 106-111, 2006.

[15] P. I. Santosa, "Measuring User Experience During a Web-based Survey: A Case of Back-to-Back Online Surveys," vol. 6, no. 3, pp. 339-344, 2016.

[16] Y. Mariam Azwa and J. Azrul Hazri, "User Experience Design ( UXD ) of Mobile Application : An Implementation of a Case Study User Experience Design ( UXD ) of Mobile Application: An Implementation of a Case Study," vol. 9, no. November, pp. 197-200, 2017.

[17] M. Zarour and M. Alharbi, "User experience framework that combines aspects, dimensions, and measurement methods," Cogent Eng., vol. 4, no. 1, pp. 1-25, 2017.

[18] R. Baharuddin, D. Singh, and R. Razali, "Usability dimensions for mobile applications-a review," Res. J. Appl. Sci. Eng. Technol., vol. 5, no. 6, pp. 2225-2231, 2013. 
[19] S. S. Tee, T. S. M. T. Wook, and S. Zainudin, "User testing for moodle application," Int. J. Softw. Eng. its Appl., vol. 7, no. 5, pp. 243-252, 2013

[20] U. Bakar and A. Jaafar, "Visual interaction patterns of students' feedback: Reliability and usability of Teaching and Supervision Evaluation System (TESES)," Lect. Notes Comput. Sci. (including Subser. Lect. Notes Artif. Intell. Lect. Notes Bioinformatics), vol. 8237 LNCS, pp. 776-787, 2013.

[21] R. Rusdi, S. Fadzilah, and M. A. T. Noor, "Usability guidelines for elderly website interface," vol. 6, no. 2, 2017.

[22] N. Rahim, T. S. M. T. Wook, N. A. M. Zin, N. A. Rawi, and R. Muda, "Usability evaluation of a virtual museum environment: Acase study in terengganu state museum, malaysia," Adv. Sci. Lett., vol. 22, no. 10, pp. 2780-2784, 2016.

[23] A. Holzinger, P. Kosec, G. Schwantzer, M. Debevc, R. HofmannWellenhof, and J. Frühauf, "Design and development of a mobile computer application to reengineer workflows in the hospital and the methodology to evaluate its effectiveness," J. Biomed. Inform, vol. 44, no. 6, pp. 968-977, 2011.

[24] A. H. H. M. Mohamed, H. Tawfik, D. Al-jumeily, and L. Norton, "MoHTAM : A Technology Acceptance Model for Mobile Health Applications," 2011.

[25] K. Thiruvanackan and M. Y. Maryati, "Penilaian Penggunaan Aplikasi Mudah Alih Kesihatan (mHealth) Dari Perspektif Ahli Farmasi,”pp. 37-54, 2017.

[26] R. Shibl, M. Lawley, and J. Debuse, "Factors in fluencing decision support system acceptance," Decis. Support Syst., vol. 54, no. 2, pp. 953-961, 2013.

[27] S. Ouma, M. Herselman, and D. Van Grauen, "Essential UX metrics to be considered when designing m-health applications in order to provide positive user experiences," Proc. IADIS Int. Conf. eHealth
2010 EH Part IADIS Multi Conf. Comput. Sci. Inf. Syst. 2010 MCCSIS 2010, no. June 2015, pp. 271-274, 2010.

[28] R. Harrison, D. Flood, and D. Duce, "Usability of mobile applications: literature review and rationale for a new usability model," pp. 1-16, 2013

[29] S. Adikari, C. Mcdonald, and J. Campbell, "User Experience in HMI : An Enhanced Assessment Model," pp. 304-310, 2010.

[30] M. Thüring and S. Mahlke, "Usability, aesthetics and emotions in human-technology interaction," Int. J. Psychol., vol. 42, no. 4, pp. 253-264, 2007.

[31] P. Morville, "User Experience Design," User Experience Design. [Online] Semantic Studios. Available at: http://semanticstudios.com/user_experience_design/ [Accessed 9 Aug. 2018], 2001. .

[32] C. H. Lu, J. L. Hsiao, and R. F. Chen, "Factors determining nurse acceptance of hospital information systems," CIN - Comput. Informatics Nurs., vol. 30, no. 5, pp. 257-264, 2012.

[33] S. Ashar Adawiyah, Meng Chun Lam, Khaldun Ismail, "A Preliminary Study on the Decision Support Mobile Application for Remote Snakebite Management Consultation in Malaysia," 3rd Int. Conf. Appl. Sci. Technol. 2018, 10-12 April 2018, Penang, Malaysia., 2018.

[34] F. Y. Pai and K. I. Huang, "Applying the Technology Acceptance Model to the introduction of healthcare information systems,' Technol. Forecast. Soc. Change, vol. 78, no. 4, pp. 650-660, 2011.

[35] S. Mahlke and S. Str, "Factors influencing the experience of website usage," pp. 846-847, 2002.

[36] D. Witarsyah, T. Sjafrizal, M. F. Fudzee, and M. A. Salamat, "The Critical Factors Affecting E-Government Adoption in Indonesia: A Conceptual Framework," vol. 7, no. 1, pp. 160-167, 2017. 